Có sự khác biệt này giữa nghiên cứu của chúng tôi và một số nghiên cứu khác có thể là do nghiên cứu của chúng tôi có cõ̃ mẫu nhỏ nên tính đại diên chưa cao.

Sự cải thiện hoạt động ăn, vệ sinh đầu mặt, mặc quần áo, sử dụng Toilet, dịch chuyển, di chuyển, lên xuống cầu thang đều có ý nghĩa thống kê $p<0,01$. Có được sự cải thiện trên là dựa vào các chiến thuật của hoạt động trị liệu không những tạo thuận, tăng sức mạnh cơ cho bên liệt mà còn có các chiến thuật bù trừ. Cho người bệnh sử dụng dụng cụ thích nghi, định hướng vào các hoạt động chức năng để cải thiện khả năng độc lập trong các sinh hoạt cá nhân và dịch chuyển, di chuyển, lên xuống cầu thang.

\section{KẾT LUẦN}

Sau can thiệp 1 tháng, điểm Barthel trung bình tăng 33,67 , có $36,7 \%$ bệnh nhân cần trợ giúp trung bình, $60 \%$ bệnh nhân trợ giúp ít và 3,3\% bệnh nhân độc lập hoàn toàn, 0 bệnh nhân phụ thuộc hoàn toàn.

\section{TÀI LIẸU THAM KHẢO}

1. Lâm Thùy Mai (2019), "Đánh giá hiệu quả phục hồi chức năng chi trên ở bênh nhân liệt nứa người do nhồi máu não", Tạp chí Ý học Việt Nam, 8.

2. Lê Huy Cường (2008), "Đánh giá kết quả hoạt động trị liệu trong phục hồi chức năng vận động chi trên ở bệnh nhân tai biến chảy máu não trên lều", Luâan vằn tốt nghiệp thạc sỹ Y khoa, trường Đại học Y Hà Nội.

3. Nguyễn Thị Kim Liên (2011), " Nghiên cứu PHCN bàn tay trên bênh nhân liêt nửa người do tai biến mạch máu não", Luận án tiến sĩ Y học, Trường Điai học Y Hà Nối.

4. Kamarul Imran, Thomas J. Keegan (2020), "The change of Barthel Index scores from thetime of discharge until 3-month postdischargeamong acute stroke patients inMalaysia: A random intercept model", PMCID: PMC6301695.

5. Smith J.C.F., Walker M.F., Sunderland A., at el. (2010), An interrater reliability study of the Nottingham stroke Dressing Assessment, British Journal of Occupational Therapy, $1-2$.

6. Adams R.D, Victor.M (1993), "Discases of the spinal cord, Principles of neurology", New York 1078 - 1116.

\title{
TỔNG QUAN VỀ HIỆU QUẢ ĐÓNG CHÓP RĂNG VĨNH VIỄN BẰNG MINERAL TRIOXYDE AGGREGATE
}

\section{TÓM TẮT. \\ Mục tiêu: Tổng kết hiệu quả điều trị đóng chóp răng vĩnh viê̂n bằng Mineral Trioxyde Aggregate (MTA) theo phương pháp tổng quan có hệ thống. Phương pháp: Tổng quan nghiên cứu có hể thống với nhóm can thiệp sử dụng MTA, nhóm đối chứng sử dụng calcium hydroxide $\left(\mathrm{Ca}(\mathrm{OH})_{2}\right)$. Trên đối tượng có rằng vĩnh viễn chưa đóng chóp vì bệnh lý tủy hoại tử hoặc viêm quanh chóp mạn tính. Kểt quả: Thời gian đóng chóp trung bình của nhóm chứng dao động trong khoảng từ $1,35 \pm 0,275$ tháng đến 3,0 $\pm 2,9$ tháng, trong khi thời gian đóng chóp của nhóm đối chứng dao động từ 1,95 $\pm 0,45$ tháng đến 7,93 $\pm 2,53$ tháng. Số răng hình thành hàng rào tố chức cứng quanh chóp ở nhóm chứng từ 7 - 29 răng, ở nhóm đối chứng từ 9 - 27 răng. Tỷ lệ đóng chóp thành công trên lâm sàng của các răng ở nhóm MTA dao động trong khoảng từ $90 \%$ đến $100 \%$. Tỷ lệ đóng chóp thành công trên lâm sàng của các răng ở các nhóm}

${ }^{1}$ Viện Đào tạo Răng Hàm Mặt, Trường Đại học Y Hà Nội ${ }^{2}$ Bệnh viện Dệt May Hà Nội

Chịu trách nhiệm chính: Đỗ Thị Thanh Tâm

Email: Bacsynhakhoathanhtam@gmail.com

Ngày nhận bài: 21.6.2021

Ngày phản biện khoa học: 20.8.2021

Ngày duyệt bài: 26.8.2021

\section{Đỗ Thị Thanh Tâm ${ }^{1}$, Trịnh Thị Thái Hà ${ }^{1}$ Lê Hồng Vân' ${ }^{1}$ Cao Thị Nhung ${ }^{2}$}

đối chứng dao động trong khoảng từ 73,30\% đến 93,33\%. Tỷ lệ đóng chóp thành công trên X-quang của các răng ở nhóm MTA dao động trong khoảng từ $82,4 \%$ đến $100 \%$. Tỷ lệ đóng chóp thành công trên Xquang của các răng ở các nhóm đối chứng dao động trong khoảng từ 75\% đến 93,33\%. Kết luận: Cả hai vât liệu $\mathrm{MTA}$ và $\mathrm{Ca}(\mathrm{OH})_{2}$ đều có tỷ lệ đóng chóp thành cổng trên lâm sàng, tỷ lệ thành công trên X-quang tương tự nhau. Tuy nhiên, về thời gian hình thành hàng rào tổ chức cứng (HRTCC) quanh chóp ở nghiên cứu này của MTA ngắn hơn rõ rệt so với $\mathrm{Ca}(\mathrm{OH})_{2}$.

Tư khóa: Răng vĩnh viễn chưa đóng chóp, MTA, Apexification

\section{SUMMARY \\ APEXIFICATION OF IMMATURE PERMANENT TEETH WITH MINERAL TRIOXYDE AGGREGATE: SYSTEMATIC REVIEW}

Objectives: The aim of this study was to conduct a quantitative systematic review, including published data, comparing the efficacy of mineral trioxide aggregate as material used for the endodontic management of immature teeth. Methods: A systematic review of the intervention group using MTA, the control group using calcium hydroxide $\left(\mathrm{Ca}(\mathrm{OH})_{2}\right)$. In subjects with imature permanent teeth because of necrotizing pulp disease or chronic apical periodontitis. Results: The time required for apical 
barrier formation of MTA group range from 1,35 \pm 0,275 months to $3,0 \pm 2,9$ months while $\mathrm{Ca}(\mathrm{OH})_{2}$ group ranged from $1.95 \pm 0.45$ months to $7.93 \pm 2.53$ months. Apical barrier formation rate in the MTA group ranged from 7 to 29 teeth, in the $\mathrm{Ca}(\mathrm{OH})_{2}$ group range from 9 to 27 teeth. The clinical success rate of apical closure of teeth in the MTA group ranged from $90 \%$ to $100 \%$. The clinical success rate in the control groups ranged from $73.30 \%$ to $93.33 \%$. The radiographic success rate in the MTA group ranged from $82.4 \%$ to $100 \%$ but in the $\mathrm{Ca}(\mathrm{OH})_{2}$ groups ranged from $75 \%$ to $93.33 \%$. Conclusion: both MTA and $\mathrm{Ca}(\mathrm{OH})_{2}$ materials have similar clinical success rate and radiographic success rates. However, the time required for apical barrier formation in this study of MTA was significantly shorter than that of $\mathrm{Ca}(\mathrm{OH})_{2}$.

Keywords: Immature permanent teeth, MTA, Apexification

\section{I. ĐĂTT VẤN ĐỀ}

Các trường hợp răng vĩnh viễn chưa đóng cuống chiếm tỷ lệ khoảng 5- 10\% trong lĩnh vực nội nha và thường do các nguyên nhân chấn thương, bất thường cấu trúc răng (núm phụ), sâu răng ${ }^{7}{ }^{3}$. Quy trình điều trị các răng vĩnh viền chưa đóng cuống tủy hoại tử hoặc viêm tủy không hồi phục việc điều trị luôn gặp nhiều thách thức. Hiện nay, trên thế giới đã có rất nhiều nghiên cứu sử dụng các loại vật liệu và phương pháp khác nhau để giải quyết những khó khăn trong điêu trị. Calcium hydroxide $\left(\mathrm{Ca}(\mathrm{OH})_{2}\right)$ là vật liệu được áp dụng phổ biến trong điều trị các răng chưa đóng kín cuống nhằm kích thích tạo hàng rào tổ chức cứng (HRTCC) giúp đóng cuống chân răng ${ }^{3}$. Quá trình điều trị kéo dài làm mất nhiêuu thời gian nên bệnh nhân dễ bỏ cuộc, nguy cơ gãy vỡ răng rất cao làm tăng chi phí cho các điều trị sau này. Đó là lý do cho việc tìm kiếm một loại vật liệu mới tốt hơn. Minera trioxide aggregate (MTA) có tính tương hợp sinh học cao, cho phép tạo được hàng rào chặn cuống tức thì, sau đó có thể hàn ống tủy ngay, đồng thời kích thích quá trình lành thương tốt và tạo HRTCC quanh cuống ${ }^{6}$. Do đó, MTA có thể giải quyết được các vấn đề mà việc sử dung $\mathrm{Ca}(\mathrm{OH})_{2}$ gặp phải.

ở Việt Nam hiện nay, mới có rất ít nghiên cứu sử dụng MTA trong điều trị răng chưa đóng cuống và chưa có nghiên cứu nào tổng hợp các tài liệu về hiệu quả của MTA. Từ những lý do trên, chúng tôi thực hiện nghiên cứu: Tổng quan về hiệu quả đóng chóp răng vĩnh viễn bằng Mineral Trioxyde Aggregate với mục tiêu: Tổng kết hiệu quả điều trị đóng chóp rắng vĩnh viễn bằng Mineral Trioxyde Aggregate theo phương pháp tổng quan có hệ thống.

\section{II. ĐỐI TƯƠNG VÀ PHƯƠNG PHÁP NGHIÊN CỨU}

2.1. Đối tượng nghiên cứu. Đối tượng nghiên cứu là những bài bào tìm được trên các cơ sở dữ liệu y học, có liên quan đến mục tiêu nghiên cứu, được tìm kiếm, thu thập và chọn lọc dựa trên trình tự mô tả trong phương pháp nghiên cứu.

2.2 Thời gian thực hiện nghiên cứu: từ $8 / 2020$ đến tháng $5 / 2021$.

2.3. Thiết kế nghiên cứu. Nghiên cứu được thực hiện theo chuẩn nghiên cứu Systematic Reviews theo hướng dẫn của Cochrane Handbook for Systematic Reviews of Interventions ${ }^{4}$ và tổng quan y văn PRISMA (Preferred Reporting Items for Systematic Review and Meta-analysis) ${ }^{2}$.

\subsection{Phương pháp thu thập thông tin}

Khung PICOTS. Các tiêu chí sau đây được sử dụng để xác định liệu một nghiên cứu có được đưa vào tổng quan để đánh giá hiệu quả sử dụng MTA ở răng vĩnh viễn chưa đóng cuống (PICOTS)

P-Population (Đối tượng nghiên cứu): Người có răng vĩnh viễn chưa đóng cuống; IIntervention (Can thiệp): Các đối tượng trong các nghiên cứu phải được điều trị nội nha sử dung MTA; C-Comparison (So sánh): Nhóm so sánh sử dụng $\mathrm{Ca}(\mathrm{OH})_{2}$ trong nghiên cứu; OOutcome (Kết quả): Hiệu quả kích thích đóng cuống của MTA; T -Time (Thời gian): Tất cả các nghiên cứu được thực hiện và công bố từ tháng 01 năm 2006 cho đến tháng 12 năm 2020; SStudy design (Thiết kế nghiên cứu): Nghiên cứu can thiêp

Ngoài ra, một số tiêu chí lựa chọn bổ sung như sau: Răng vĩnh viễn chưa trưởng thành không đóng chóp vì bệnh lý tủy hoại tử hoặc viêm quanh cuống mãn tính. Các nghiên cứu được viết bằng tiếng anh và toàn văn. Xuất bản dưới dạng một bài báo gốc không phải tóm tắt. Kết quả được đánh giá bằng các triệu chứng lâm sàng và bằng chứng chụp Xquang

Tiêu chuẩn lựa chọn. Theo các tiêu chí lựa chọn từ PICOST đối với các nghiên cứu. Các nghiên cứu phải được trình bày bằng ngôn ngữ tiếng Anh.

Tiêu chí loại trừ. Các bài báo không đáp ứng tiêu chí PICÖ; Các bài dang tổng quan; Các nghiên cứu được thực hiện trong ống nghiệm và trên động vật; Các nghiên cứu mà không có sự so sánh của 2 vật liệu

Định nghĩa thành công và thất bại; Biện pháp chính là lâm sàng và kết quả chụp X-quang; Biên pháp thứ hai là đánh giá sự hình thành hàng rào tổ chức cứng quanh cuống. 
Các thông số sau được sử dụng để đánh giá mức độ thành công:

1. Về lâm sàng: răng không đau nhức, không có lỗ rò, gõ không đau.

2. $X$ quang: Vùng quanh cuống bình thường và hoàn thiện chóp chân răng.

Một kết quả thuận lợi khi răng không có triệu chứng lâm sàng và vùng quanh chóp bình thường.

1. Không có sự khác biệt về tỷ lệ các răng biểu hiện các dấu hiệu thất bại trên lâm sàng và $X$ quang sau khi điều trị 2 loại.

2. Hàng rào TCCQC của MTA có thể đạt được kết quả tương tự như dùng $\mathrm{Ca}(\mathrm{OH})_{2}$ dài hạn để tạo chóp.

Câu hỏi nghiên cứu: Đánh giá hiệu quả đóng chóp răng vĩnh viễn bằng MTA

2.6. Chiến lược tìm kiếm và nguồn dữ liệu

- Quá trình tìm kiếm được thực hiện từ 08/2020 đến 05/2021.

Cơ sở dữ liệu tra cứu: PubMed; Cochrane Library và Science Direct

Tư khóa: (((apexification) OR (root end closure)) AND ((permanent teeth) OR (permanent tooth))) OR ((immature permanent teeth) OR (immature permanent tooth)) AND ((MTA) OR (Mineral trioxide aggregate) OR (mineral tri-oxide aggregate))

2.7. Đánh giá chất lượng nghiên cứu. Đánh giá tài liệu được thực hiện bởi hai nhà kiểm duyệt. Sử dụng thang điểm của Jadad và cộng sự để đánh giá chất lượng của các tài liệu nghiên cứu. Thang đo gồm 5 tiêu chí, 3 khía cạnh. Đánh giá điểm số từ 0-5 điểm, nếu tài liệu đạt $<=2$ được cho là kém giá trị.
2.8. Trích xuất dữ liệu. Hai nhà kiểm duyệt độc lập đã sàng lọc tất cả các bài viết (theo tiêu đề và tóm tắt) dựa vào các các tiêu chí lựa chọn của khung PICOST. Sau đó, cả 2 đọc toàn vằn các nghiên cứu. Các nghiên cứu được đánh giá độc lập bởi cùng hai nhà kiểm duyệt theo các tiểu chí lựa chọn và loại trừ. Sự khác biệt được giải quyết bằng thảo luận và đồng thuận.

Trích xuất dữ liê̂u: được đánh giá bởi hai nhà kiểm duyệt từ mối nghiên cứu theo mẫu trích xuất dữ liệu Excel được tự thiết kế. Thông tin được trích xuất từ mỗi nghiên cứu gồm: tên tài liệu, tên tác giả, năm xuất bản và địa điểm nghiên cứu, thiết kế nghiên cứu, đặc điểm của người tham gia nghiên cứu (bao gồm: tuổi, giới, cơ mẫu và phương pháp chọn mẫu).

2.9. Đạo đức trong nghiên cứu. Nghiên cứu được thực hiện trên đối tượng là các dữ liệu nghiên cứu đã công bố đảm bảo các yêu cầu về đạo đức nghiên cứu.

\section{KẾT QUẢ NGHIÊN CứU}

3.1. Kết quả tìm kiếm tài liệu lọc. Từ các nguồn tìm kiếm, chúng tôi đã xác định được 2533 tài liệu qua tìm kiếm trực tuyến (Hình 3.1). Sau khi loại 274 tài liệu trùng lặp, số tài liệu được giữ lại là 2259 tài liệu. Nhóm nghiên cứu đã sàng lọc và loại đi 2215 tài liệu không liên quan theo tên đề tài và tóm tắt. Còn lại 44 tài liệu còn lại được đưa vào khâu sàng lọc thông tin toàn văn. Đã có 37 tài liệu bị loại ra do không có toàn văn (7 tài liệu) và không liên quan đến phương pháp can thiệp (30 tài liệu). 7 tài liệu toàn văn được giữ lại để trích xuất các thông tin cho nghiên cứu.

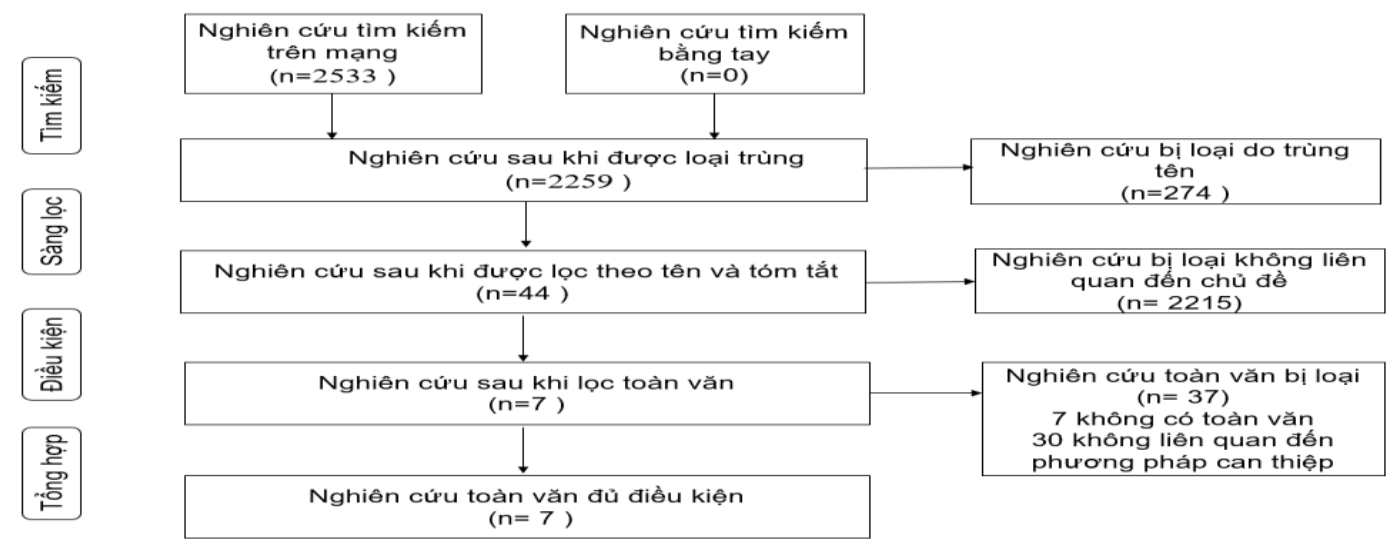

Hình 3.1 . Sơ đồ PRISMA

3.2. Đánh giá chất lượng của các nghiên cứu. Có 3 nghiên cứu đạt 2 điểm, có 2 nghiên cứu đạt 3 điểm và có 1 nghiên cứu của G Kandemir Demirci đạt điểm tối đa là 5 điểm. Tất cả các nghiên cứu đều có điểm số cho tính ngẫu nhiên, đa số đều có điểm số cho phần mô tả về bỏ cuộc và mất đối tượng nghiên cứu, còn điểm số cho làm mù thì chỉ có 2 nghiên cứu. 
Bảng 3.1. Bảng đánh giá chất lượng của các nghiên cứu

\begin{tabular}{|c|c|c|c|c|}
\hline Tác giả và năm công bố & $\begin{array}{c}\text { Mô tả ngấu } \\
\text { nhiên }\end{array}$ & $\begin{array}{c}\text { Mố tả làm } \\
\text { mù }\end{array}$ & $\begin{array}{c}\text { Mô tả đối tượng } \\
\text { bỏ cuộc }\end{array}$ & $\begin{array}{c}\text { Tổng } \\
\text { điểm }\end{array}$ \\
\hline EL-Emyli and Avery, 2006 & 1 & 1 & 1 & 3 \\
\hline DP.Pradhan, 2006 & & & 1 & 1 \\
\hline S.Damle, 2012 & 2 & 0 & 1 & 3 \\
\hline Li-Wan Lee, 2014 & 1 & 0 & 1 & 2 \\
\hline Eric Bontem, 2014 & 1 & 0 & 1 & 2 \\
\hline SG.Damle, 2016 & 2 & 0 & 0 & 2 \\
\hline G.Kandemir Demirci, 2020 & 2 & 2 & 1 & 5 \\
\hline
\end{tabular}

3.3. Đăc điểm của các tài liệu nghiên cứu. Trong tổng số 6 tài liệu được chọn đều nằm trong khoảng thời gian từ năm 2006-2020. Có 3 tài liệu nghiên cứu đều được thực hiện ở Ấn Độ, còn tại Ai Cập, Trung Quốc, Pháp và Thổ Nhĩ Kỳ. Cõ̃ mẫu trước can thiệp nằm trong khoảng từ 15-90, cõ mẫu sau can thiệp từ 15-73. Đa phần các đối tượng đều là trẻ em có độ tuổi trong khoảng từ 6-18 tuổi. Các răng được chọn ở đây là các răng bị hoại tử, tổng số răng trong các nghiên cứu là 182 răng dao động từ 20-90 răng. Các nhóm can thiệp đều thực hiện MTA. Nhóm đối chứng thực hiện loại hình can thiệp là $\mathrm{Ca}(\mathrm{OH})_{2}$.

Bảng 3.3 Đặc điểm các can thiệp

\begin{tabular}{|c|c|c|c|c|c|c|c|c|}
\hline \multirow[b]{2}{*}{$\begin{array}{l}\text { Tác giả và } \\
\text { năm công } \\
\text { bố }\end{array}$} & \multirow[b]{2}{*}{$\begin{array}{l}\text { Đia } \\
\text { điểm }\end{array}$} & \multirow[b]{2}{*}{$\begin{array}{c}\text { Thiết } \\
\text { kế }\end{array}$} & \multicolumn{2}{|c|}{ Cỡ mấu } & \multirow[b]{2}{*}{ Đối tượng } & \multirow[b]{2}{*}{ Số răng } & \multicolumn{2}{|c|}{ Loại hình can thiệp } \\
\hline & & & $\begin{array}{l}\text { Trước } \\
\text { can } \\
\text { thiêp }\end{array}$ & $\begin{array}{l}\text { Sau } \\
\text { can } \\
\text { thiêp }\end{array}$ & & & $\begin{array}{l}\text { Nhóm } \\
\text { can } \\
\text { thiêp }\end{array}$ & $\begin{array}{l}\text { Nhóm đối } \\
\text { chứng }\end{array}$ \\
\hline $\begin{array}{l}\text { EL-Emyli } \\
\text { and Avery, } \\
2006\end{array}$ & $\begin{array}{l}\text { Ai } \\
\text { Cập }\end{array}$ & RCT & 15 & 15 & $\begin{array}{c}\text { Trẻ 6-12 tuổi có } \\
\text { răng vĩnh viê̂n } \\
\text { chưa trưởng thành } \\
\text { bị chấn thương } \\
\text { hoă̆c hoại tử } \\
\text { nghiêm trọng }\end{array}$ & $\begin{array}{c}30 \text { răng: } 24 \text { răng } \\
\text { cửa hàm trên và } 6 \\
\text { răng cửa bên hàm } \\
\text { trên }\end{array}$ & MTA & $\mathrm{Ca}(\mathrm{OH})_{2}$ \\
\hline $\begin{array}{l}\text { DP.Pradhan, } \\
2006\end{array}$ & $\begin{array}{l}\text { Ấn } \\
\text { Độ }\end{array}$ & RCT & 16 & 16 & $\begin{array}{c}\text { Trẻ em từ } 8 \text { đến } \\
15 \text { tuổi có răng } \\
\text { vĩnh viễn, chưa } \\
\text { trưởng thành, vĩnh } \\
\text { viễn }\end{array}$ & $\begin{array}{c}20 \text { răng cửa hàm } \\
\text { trên: } 19 \text { răng cửa } \\
\text { ở giữa và } 1 \text { răng } \\
\text { cửa bên }\end{array}$ & MTA & $\mathrm{Ca}(\mathrm{OH})_{2}$ \\
\hline $\begin{array}{l}\text { S.Damle, } \\
2012\end{array}$ & $\begin{array}{l}\text { Ấn } \\
\text { Độ }\end{array}$ & RCT & 20 & 20 & $\begin{array}{l}\text { Trẻ từ 8-12 tuổi có } \\
\text { vĩnh viến cuống } \\
\text { hoại tử và chóp hở }\end{array}$ & $\begin{array}{l}30 \text { răng, } 10 \text { trẻ bị } \\
\text { gãy một chiếc } \\
\text { răng và } 10 \text { trẻ } \\
\text { khác bị gãy hai } \\
\text { răng (hai răng } \\
\text { cửa giữa hoặc gãy } \\
1 \text { răng của giữa } \\
\text { và } 1 \text { răng của bên }\end{array}$ & MTA & $\mathrm{Ca}(\mathrm{OH})_{2}$ \\
\hline $\begin{array}{l}\text { Li-Wan } \\
\text { Lee, } \\
2014\end{array}$ & $\begin{array}{l}\text { Trung } \\
\text { Quốc }\end{array}$ & RCT & 40 & 40 & $\begin{array}{c}\text { Trẻ 6,5-10 tuổi có } \\
\text { răng cửa hở chóp } \\
\text { hoại tử }\end{array}$ & $\begin{array}{c}40 \text { răng, } 32 \text { răng } \\
\text { cửa trung tâm hàm } \\
\text { trên, } 4 \text { răng cửa bên } \\
\text { hàm trên và } 4 \text { răng } \\
\text { cứa trung tâm hàm } \\
\text { dưới. } 20 \text { răng cửa } \\
\text { có đỉnh chân răng } \\
<2 \mathrm{~mm}, 20 \text { răng } \\
\text { cửa có đỉnh từ } 2- \\
3,5 \mathrm{~mm}\end{array}$ & $\begin{array}{c}\text { Máy } \\
\text { nội nha } \\
\text { dung } \\
\text { rửa } \\
\text { siêu } \\
\text { âm và } \\
\text { MTA }\end{array}$ & $\begin{array}{c}\text { Máy nôi nha } \\
\text { dung rửa siêu } \\
\text { âm và } \\
\mathrm{Ca}(\mathrm{OH})_{2} ; \\
\text { Dùng tay và } \\
\text { MTA; Dùng } \\
\text { tay và thuốc } \\
\mathrm{Ca}(\mathrm{OH})_{2}\end{array}$ \\
\hline $\begin{array}{c}\text { Eric } \\
\text { Bontem, }\end{array}$ & Pháp & RCT & 30 & 30 & $\begin{array}{l}\text { Trẻ từ 6-18 tuổi có } \\
\text { răng cửa vĩnh viê̂n }\end{array}$ & 30 răng cửa & MTA & $\mathrm{Ca}(\mathrm{OH})_{2}$ \\
\hline
\end{tabular}




\begin{tabular}{|c|c|c|c|c|c|c|c|c|}
\hline 2014 & & & & & $\begin{array}{c}\text { chưa trưởng thành } \\
\text { bị hoại tử }\end{array}$ & & & \\
\hline $\begin{array}{l}\text { SG.Damle, } \\
2016\end{array}$ & $\begin{array}{l}\text { Ấn } \\
\text { Độ }\end{array}$ & RCT & 22 & 22 & $\begin{array}{c}\text { Trẻ 8-13 tuổi gãy } \\
\text { răng cửa răng vĩnh } \\
\text { viễn hàm trên }\end{array}$ & $\begin{array}{c}22 \text { răng cưa, } 20 \\
\text { răng cửa trung } \\
\text { tâm, răng cửa bên } \\
\text { chỉ có } 2 \text { trẻ. }\end{array}$ & MTA & $\mathrm{Ca}(\mathrm{OH})_{2}$ \\
\hline $\begin{array}{l}\text { G.Kandemir } \\
\text { Demirci, } \\
2020\end{array}$ & $\begin{array}{l}\text { Thổ } \\
\text { Nhĩ } \\
\text { Kỳ }\end{array}$ & RCT & 90 & 73 & $\begin{array}{c}\text { Bệnh nhân từ 18- } \\
40 \text { tuổi có răng } \\
\text { chưa trưởng thành } \\
\text { có vết hoại tử và } \\
\text { tổn thương quanh } \\
\text { răng }\end{array}$ & $\begin{array}{l}90 \text { răng trước } \\
\text { hàm trên }\end{array}$ & MTA & $\mathrm{Ca}(\mathrm{OH})_{2}$ \\
\hline
\end{tabular}

3.5 Hiệu quả đóng chop. Thời gian đóng cuống trung bình của nhóm chứng dao động trong khoảng từ $1,35 \pm 0,275$ tháng đến $3,0 \pm$ 2,9 tháng, trong khi thời gian đóng cuống của nhóm đối chứng dao động từ 1,95 $\pm 0,45$ tháng đến 7,93 $\pm 2,53$ tháng. Số răng hình thành hàng rào mô cứng ở đỉnh ở nhóm chứng từ 7-29 răng, ở nhóm đối chứng từ 9-27 răng. ở nhóm chứng có Số răng hình thành hàng rào mô cứng ở đỉnh cao hơn hoặc bằng nhóm đối chứng, chỉ có một nghiên cứu của DP.Pradhan là nhóm MTA có số răng ít hơn. Đa phần thời gian thời gian theo dõi để đạt được tỷ lệ đóng cuống thành công là 12 tháng, chỉ có 1 nghiên cứu 9 tháng và 1 nghiên cứu 12 tháng. Tỷ lệ đóng cuống thành công trên lâm sàng của các răng ở nhóm MTA dao động trong khoảng từ $90 \%$ đến $100 \%$. Tỷ lệ đóng cuống thành công trên lâm sàng của các răng ở các nhóm chứng dao động trong khoảng từ $73,3 \%$ đến $93,33 \%$. Tỷ lệ đóng cuống thành công trên X-quang của các răng ở nhóm MTA dao động trong khoảng từ $82,4 \%$ đến $100 \%$. Tỷ lệ đóng cuống thành công trên X-quang của các rằng ở các nhóm chứng dao động trong khoảng từ $75 \%$ đến $93,33 \%$. Tóm lại, tỷ lệ đóng cuống thành công trên lâm sàng và trên $X$-quang của nhóm sử dụng MTA đều cao hơn so với các nhóm sử dụng vật liệu là $\mathrm{Ca}(\mathrm{OH})_{2}$ nhưng không chênh lêch quá nhiều, chỉ có một nghiên cứu của DP.Pradhan là có tỷ lệ đóng cuống của nhóm MTA thấp hơn nhóm $\mathrm{Ca}(\mathrm{OH})_{2}$.

Bảng 3.4 Hiệu quả đóng chóp răng vĩnh viễn

\begin{tabular}{|c|c|c|c|c|c|c|c|c|c|}
\hline \multirow{2}{*}{$\begin{array}{l}\text { Tác giả và } \\
\text { năm công } \\
\text { bố }\end{array}$} & \multicolumn{2}{|c|}{$\begin{array}{l}\text { Thời gian hình } \\
\text { thành HRTCC } \\
\text { (tháng) }\end{array}$} & \multicolumn{2}{|c|}{$\begin{array}{l}\text { Hình thành } \\
\text { HRTCC } \\
\text { (răng) }\end{array}$} & \multirow{2}{*}{$\begin{array}{c}\text { Thời } \\
\text { gian } \\
\text { theo } \\
\text { dõi }\end{array}$} & \multicolumn{2}{|c|}{\begin{tabular}{|c|}
$\begin{array}{c}\text { Tỷ lệ thành công } \\
\text { trên lâm sàng } \\
(\%)\end{array}$ \\
\end{tabular}} & \multicolumn{2}{|c|}{\begin{tabular}{|c|}
$\begin{array}{c}\text { Tỷ lệ thành công } \\
\text { trên } x-q u a n g \\
(\%)\end{array}$ \\
\end{tabular}} \\
\hline & $\begin{array}{l}\text { Nhóm } \\
\text { chứng }\end{array}$ & $\begin{array}{l}\text { Nhóm đối } \\
\text { chứng }\end{array}$ & $\begin{array}{l}\text { Nhóm } \\
\text { chứng }\end{array}$ & $\begin{array}{l}\text { Nhóm } \\
\text { đối } \\
\text { chứng }\end{array}$ & & $\begin{array}{l}\text { Nhóm } \\
\text { chứng }\end{array}$ & $\begin{array}{c}\text { Nhóm } \\
\text { đối } \\
\text { chứng }\end{array}$ & $\begin{array}{l}\text { Nhóm } \\
\text { chứng }\end{array}$ & $\begin{array}{l}\text { Nhóm } \\
\text { đối } \\
\text { chứng }\end{array}$ \\
\hline $\begin{array}{l}\text { EL-Emyli and } \\
\text { Avery, } 2006\end{array}$ & & & 15 răng & 13 răng & $\begin{array}{c}12 \\
\text { tháng }\end{array}$ & $100 \%$ & $86,67 \%$ & $100 \%$ & $86,67 \%$ \\
\hline $\begin{array}{l}\text { DP.Pradhan, } \\
2006\end{array}$ & $\begin{array}{c}3,0 \pm \\
2,9\end{array}$ & $7,0 \pm 2,5$ & 7 răng & 10 răng & & $100 \%$ & $100 \%$ & & \\
\hline $\begin{array}{c}\text { S.Damle, } \\
2012\end{array}$ & $\begin{array}{c}4,5 \pm \\
1,56\end{array}$ & $7,93 \pm 2,53$ & 15 răng & 14 răng & $\begin{array}{c}12 \\
\text { tháng }\end{array}$ & $100 \%$ & $93,33 \%$ & $100 \%$ & $93,33 \%$ \\
\hline $\begin{array}{l}\text { Li-Wan Lee, } \\
2014\end{array}$ & $\begin{array}{c}1,35 \pm \\
0,275 \\
\end{array}$ & $\begin{array}{c}\text { Nhóm 1: } \\
\text { 2,825 } \\
0,325 ; \text { Nhóm } \\
2: 1,95 \pm \\
0,45 ; \text { nhóm 3: } \\
3,275 \pm 0,375\end{array}$ & & & & & & & \\
\hline $\begin{array}{c}\text { Eric Bontem, } \\
2014\end{array}$ & & & 13 răng & 8 răng & $\begin{array}{c}12 \\
\text { tháng }\end{array}$ & $100 \%$ & $73,3 \%$ & $82,4 \%$ & $75 \%$ \\
\hline $\begin{array}{c}\text { SG.Damle, } \\
2016\end{array}$ & 4,9 & 5,33 & 10 răng & 9 răng & 9 tháng & $90,90 \%$ & $81,81 \%$ & $90,90 \%$ & $81,81 \%$ \\
\hline $\begin{array}{c}\text { G.Kandemir } \\
\text { Demirci, } 2020\end{array}$ & & & 29 răng & 27 răng & $\begin{array}{c}48 \\
\text { tháng }\end{array}$ & $90 \%$ & $91 \%$ & $90 \%$ & $91 \%$ \\
\hline
\end{tabular}




\section{BÀN LUÂ̂N}

Nghiên cứu của chúng tôi được thực hiên bằng phương pháp tổng quan hệ thống hệ thống với 6 tài liệu RCT từ năm 2006-2020. Nghiên cứu được thực hiện chủ yếu ở đối tượng từ 6-18 tuổi. Trong nghiên cứu này chúng tôi đã tổng kết hiệu quả điều trị đóng chóp răng vinnh viễn bằng MTA so với $\mathrm{Ca}(\mathrm{OH})_{2}$. Kết quả cho thấy cả hai vật liệu đều có hiệu quả đóng chóp cả trên lâm sàng và trên X-quang. Nhưng MTA cho thây hiệu quả đóng chóp răng vĩnh viễn cao hơn hẳn so với $\mathrm{Ca}(\mathrm{OH})_{2}$. Thời gian đóng cuống của MTA cũng ngẳn hơn so với $\mathrm{Ca}(\mathrm{OH})_{2}$.

Trên thế giới, đến thời điểm hiện tại có một số nghiên cứu tổng quan hệ thống đánh giá về hiệu quả đóng chóp ở răng vĩnh viễn chưa trưởng thành. Tuy nhiên, các nghiên cứu được thực hiện ở thời gian trong khoảng từ năm 20112019, do đó các tài liệu mới nhất về hiệu quả đóng chóp răng ở MTA chưa được cập nhật mới nhất. Một nghiên cứu của Jia-Cheng Lin ${ }^{5}$ được thực hiện tại Hàn Quốc với kết quả là 4 tài liệu RCT được chọn lọc vào nghiên cứu, nghiên cứu này cũng chỉ ít hơnn nghiên cứu của chúng tôi 3 tài liệu. Điều này có thể giải thích là do nghiên cứu của Jia-Cheng Lin được thực hiện từ đầu năm 2016 nên có 2 nghiên cứu được chúng tôi cập nhật hơn vào năm 2016 và năm 2020.

Nghiên cứu của chúng tôi trên trẻ em có độ tuổi từ 6-18 tuổi, còn nghiên cứu của Jia-Cheng Lin ${ }^{5}$ cũng có đối tượng là trẻ em từ 6-12 tuổi, một nghiên cứu khác cũng phù hợp với nghiên cứu của chúng tôi được thực hiện ở trẻ 6-14 tuổi ${ }^{1}$. Số lượng răng trong nghiển cứu này (182 răng) cũng lớn hơn nhiều so với nghiên cúa của Jia-Cheng Lin (80 răng) ${ }^{5}$ và nghiên cứu của Sanaa Chala (50 răng $)^{9}$, nhưng lại ít hơn số răng trong nghiên cứu được thực hiện vào năm 2019 (232 răng) ${ }^{1}$.

Tỷ lệ đóng cuống thành công trên lâm sàng của các răng ở nhóm MTA dao động trong khoảng từ $90 \%$ đến $100 \%$, của $\mathrm{Ca}(\mathrm{OH})_{2}$ từ $73,3 \%$ đến $93,33 \%$. Tỷ lệ đóng cuống thành công trên X-quang của các răng ở nhóm MTA dao động trong khoảng từ $82,4 \%$ đến $100 \%$ $\mathrm{Ca}(\mathrm{OH})_{2}$ từ $75 \%$ đến $93,33 \%$. Cả MTA và $\mathrm{Ca}(\mathrm{OH})_{2}$ đều có tỷ lệ đóng cuống thành công trên lâm sàng, tỳ lệ thành công trên $X$ quang tương tư nhau. Điều này tương tư với kết quả của một nghiên cứu tổng quan tài liệu của một tác giả Sanaa Chala9 ${ }^{9}$. Tương tự, nghiên cứu của Jia-Cheng Lin $^{5}$ chỉ ra tỷ lệ thành công trên lâm sàng của $\mathrm{MTA}$ từ $93 \%$ đến $100 \%$ và $\mathrm{Ca}(\mathrm{OH})_{2}$ là từ $87 \%$ đến $100 \%$. Còn tỷ lệ thành công trên phim Xquang của nhóm MTA là $100 \%$ còn nhóm
$\mathrm{Ca}(\mathrm{OH})_{2}$ là từ $87 \%$ đến $93 \%$. Về thời gian hình thành HRTCC ở nghiên cứu này của MTA $(1,35 \pm$ 0,275 tháng đến $3,0 \pm 2,9$ tháng) ngắn hơn so với $\mathrm{Ca}(\mathrm{OH})_{2}(1,95 \pm 0,45$ tháng đến $7,93 \pm 2,53$ tháng) kết quả này phù hợp với kết quả trong nghiên cứu ảa Jia-Cheng Lin ${ }^{5}$ và tác giả Sanaa Chala .

Thời gian đóng cuống trung bình của nhóm chứng dao động trong khoảng từ $1,35 \pm 0,275$ tháng đến 3,0 $\pm 2,9$ tháng, trong khi thời gian đóng cuống của nhóm đối chứng dao động từ $1,95 \pm 0,45$ tháng đến 7,93 $\pm 2,53$ tháng.

\section{KẾT LUÂN}

Cả hai vật liệu MTA và $\mathrm{Ca}(\mathrm{OH})_{2}$ đều có tỷ lệ đóng cuống thành công trên lâm sàng, tỷ lệ thành công trên $X$ quang tương tự nhau. Tuy nhiên, Về thời gian hình thành HRTCC ở nghiên cứu này của MTA $(1,35 \pm 0,275$ tháng đến $3,0 \pm$ 2,9 tháng) ngắn hơn rõ rệt so với $\mathrm{Ca}(\mathrm{OH})_{2}(1,95$ $\pm 0,45$ tháng đến 7,93 $\pm 2,53$ tháng).

\section{TÀI LIÊU THAM KHẢO}

1. Yuan Chen. Materials for pulpotomy in immature permanent teeth: a systematic review and metaanalysis - PubMed. Accessed August 20, 2021. https://pubmed.ncbi.nlm.nih.gov/31647004/

2. Moher D, Liberati A, Tetzlaff J, Altman DG, PRISMA Group. Preferred reporting items for systematic reviews and meta-analyses: the PRISMA statement. Int J Surg Lond Engl. 2010;8(5):336-341. doi:10.1016/j.ijsu.2010.02.007

3. Plascencia $H$, Díaz $M$, Gascón $G$, et al. Management of permanent teeth with necrotic pulps and open apices according to the stage of root development. J Clin Exp Dent. 2017;9(11):e1329-e1339. doi:10.4317/jced.54287

4. Higgins JPT, Thomas $J$, Chandler $J$, et al. Cochrane Handbook for Systematic Reviews of Interventions. John Wiley \& Sons; 2019.

5. Jia-Cheng Lin. Comparison of mineral trioxide aggregate and calcium hydroxide for apexification of immature permanent teeth: A systematic review and meta-analysis - PubMed. Accessed August 20, 2021. https://pubmed.ncbi.nlm.nih.gov/26911724/

6. Torabinejad M, Hong CU, McDonald F, Pitt Ford TR. Physical and chemical properties of a new root-end filling material. J Endod. 1995; 21(7): 349-353. doi:10.1016/S0099-2399(06) 80967-2

7. Rafter M. Apexification: a review. Dent Traumatol Off Publ Int Assoc Dent Traumatol. 2005;21(1):1-8. 9657.2004.00284.x

8. No Authour. Appendix: Jadad Scale for Reporting Randomized Controlled Trials. In: Evidence-Based Obstetric Anesthesia. John Wiley \& Sons, Ltd; 2005:237-238. doi:10.1002/ 9780470988343.app1

9. Chala S, Abouqal R, Rida S. Apexification of immature teeth with calcium hydroxide or mineral trioxide aggregate: systematic review and metaanalysis. Oral Surg Oral Med Oral Pathol Oral Radiol Endod. 2011;112(4):e36-42. doi:10.1016/j.tripleo.2011.03.047 